\title{
AUTOEXÍLIO E MEMÓRIA EM DUBLINENSES
}

\author{
Cristiane Antunes ${ }^{1}$ \\ Rosani Umbach ${ }^{2}$ \\ Sabrina Siqueira ${ }^{3}$
}

Resumo: Este estudo considera a influência do autoexílio do escritor James Joyce na composição de seus contos, compilados sob o título Dublinenses e publicados pela primeira vez em 1914. Joyce troca cartas com amigos e parentes para saber detalhes sobre acontecimentos e moradores de Dublin, e assim transportar para a narrativa dos contos nuances de sua terra natal.

Palavras-chave: Autoexílio; Dublinenses; James Joyce; memória.

Abstract: This work considers the influence of writer James Joyce's self-exile in the composition of his short stories, compiled under the title Dubliners and published for the first time in 1914. Joyce exchanges letters with family and friends to know details about events and residents of Dublin, and then to carry nuances of his homeland to the narrative of the short stories

Keywords: Self-exile; Dubliners; James Joyce; memory.

James Joyce nasceu em Dublin em 1882, no entanto viveu a maior parte de sua vida fora da Irlanda. A obra de Joyce, não obstante a ausência do autor de sua terra natal, está totalmente ligada ao país, o qual ele ajudou a colocar no mapa dos grandes cenários literários. Sobre isso, Alan Noronha Corrêa, em seu estudo: "How to Build an Irish Artist: Joyce's First Portraits of Dublin",

\footnotetext{
${ }^{1}$ Doutoranda em Letras - Estudos Literários pela UFSM e integrante do Grupo de Estudos Literatura e Autoritarismo.

2 Professora Doutora no Programa de Pós-Graduação em Letras Estudos-Literários, Linha de Pesquisa Literatura, Comparatismo e Crítica Social, e coordenadora do Grupo de Estudos Literatura e Autoritarismo.

${ }^{3}$ Doutoranda em Letras - Estudos Literários pela UFSM e integrante do Grupo de Estudos Literatura e Autoritarismo.
} 
considera que "this self-imposed exile can be seen as representing the need of the artist to step back to a certain distance from his object so as to better apprehend it and shape it aesthetically"4 (2012, p.8). Richard Ellmann (1989), por sua vez, em sua obra James Joyce, explica que para ter a medida de si mesmo e de seu país, Joyce precisava tomar as medidas de um mundo alheio. Segundo Edna O'Brien, em sua obra homônima à de Ellmann, afirma que para Joyce "a Irlanda ia tornar-se o fermento de sua imaginação, com os esteios gêmeos da memória e do exílio" (2001, p. 50). Com o conjunto de sua obra, o escritor irlandês acreditava ter feito "uma recriação tão fantástica que calculava que serviria de planta se a cidade um dia fosse destruída" (O'BRIEN, 2001, p. 106).

Conforme o relato desses estudiosos da vida de James Joyce, o escritor optou pelo autoexílio porque, para ele, a vida artística em Dublin parecia tão estreita, pequena e restritiva quanto sua vida doméstica, cheia de brigas por religião e política. Joyce recusou convite para fazer parte da Academia de Letras Irlandesa em função de sua tendência ao isolamento e por considerar que seu projeto literário seguia uma direção diferente dos trabalhos propostos pela Academia, como, por exemplo, sua liberdade na utilização das palavras e seus experimentos com a linguagem presentes principalmente em suas últimas obras.

Outro motivo pelo qual o escritor não se entusiasmou com a possibilidade de fazer parte da Academia foi sua descrença em sociedades literárias, as quais considerava ingênuas, dotadas de um tipo de nacionalismo cego. Com os contos, Joyce não ofereceu um retrato terno e virtuoso da Irlanda; não proclamou um passado místico celta nem cantou a terra idílica gloriosa. Ao invés disso, brindou seus conterrâneos e o mundo com uma escrita realista e visão pormenorizada do cotidiano, com uma agudeza impressionante em suas observações e histórias da vida urbana irlandesa, com seus defeitos e sordidez. Sobre os temas dos contos de Joyce, Paulo Vizioli, em James Joyce e sua obra literária, afirma:

\footnotetext{
4 "Esse exílio auto imposto pode ser visto como representativo da necessidade do artista de se distanciar do seu objeto para melhor apreendê-lo e moldá-lo esteticamente". (Tradução livre nossa, bem como as demais traduções ao longo deste trabalho.)
} 
Para ele, a atmosfera cultural de Dublin era mesmo irremediavelmente provinciana e asfixiante. Portanto, era sobre isso que tinha de escrever, retratando a pobreza material e moral a seu redor, o despropósito de tudo, e a sua frustração de homem e de artista (VIZIOLI, 1991, p. 21).

De acordo com biógrafos e estudiosos de Joyce, os contos não foram escritos na ordem em que estão organizados no livro. Segundo eles, a ordem de escrita foi aleatória e alguns contos partiram de anotações avulsas que o autor fazia de momentos do cotidiano, aos quais denominava "epifanias" ou "instantes promissores", apesar de sua aparente banalidade. Quando decidiu transformar essas anotações em contos, Joyce o fez com intuito comercial, tendo vendido algumas dessas histórias para jornais e revistas de literatura. $\mathrm{O}$ primeiro conto escrito foi "As irmãs", publicado no jornal Irish Homestead, em 13 de agosto de 1904. Logo em seguida, ainda escritos enquanto o autor encontrava-se em Dublin, vieram "Eveline" e "Depois da corrida", publicados, respectivamente, em 10 de setembro e 17 de dezembro daquele mesmo ano. A próxima história finalizada foi "Uma mãe", inspirada em uma apresentação no Ancient Concert Rooms em que o próprio James participou como cantor e cuja pianista saiu bruscamente no intervalo do espetáculo.

Três contos foram adicionados depois de a coleção já estar organizada e ter sido apresentada (e recusada) a alguns editores: "Dois galanteadores", "Uma pequena nuvem" e "Os mortos", o último escrito enquanto Joyce morava na Itália. Em cartas para casa, o escritor queixava-se de estar derretendo como manteiga no verão italiano, fato da vida empírica do escritor que remete à narrativa do conto "Os mortos", na qual o protagonista Gabriel deseja caminhar na neve, estar no vento frio. Esse pode ser considerado um exemplo importante da influência do autoexílio na obra de Joyce, já que suas experiências pessoais, como um elemento da realidade, extraestético, é transformado, por seu trabalho artístico, em elemento constitutivo de sua estética. Aqui, o elemento empírico não será visto apenas como uma referência que possibilita identificar uma determinada situação sócio espacial do autor e sim como parte da construção artística, como um fator antes determinante na construção dos sentidos da narrativa enquanto tal. Acerca disso, Antonio Candido, em seu livro Literatura e sociedade, afirma:

Revista Eletrônica Literatura e Autoritarismo: Narrativa Testemunhal e Relações Históricas - ISSN 1679-849X |117| http://cascavel.ufsm.br/revistas/ojs-2.2.2/index.php/LA/index 
neste caso, saímos dos aspectos periféricos da sociologia, ou da história sociologicamente orientada, para chegar a uma interpretação estética que assimilou a dimensão social como fator de arte. Quando isto se dá, ocorre o paradoxo assinalado inicialmente: o externo se torna interno e a crítica deixa de ser sociológica, para ser apenas crítica. O elemento social se torna um dos muitos que interferem na economia do livro, ao lado dos psicológicos, religiosos, linguísticos e outros. Neste nível de análise, em que a estrutura constitui o ponto de referência, as divisões pouco importam, pois ludo se transforma, para o crítico, em fermento orgânico de que resultou a diversidade coesa do todo (CANDIDO, 2006, p. 16).

Nos contos, Joyce trabalhou em torno destes dois conceitos: a "realidade" da qual era preciso escapar e o "ideal" que pretendia atingir através da arte. Entre esses dois polos, o escritor pontilhou fatos de sua vida privada e da jocosidade dos subúrbios dublinenses. Artesão das palavras, o escritor faz de Dublin um labirinto cheio de obstáculos que tentam impedir os habitantes de ver o que eles são e o que podem vir a realizar, até que se depararem com casos epifânicos, tenham a chance de matar o seu "Minotauro" particular e se desloquem da turbulência para a consciência da própria situação.

A metáfora do labirinto faz alusão a um estado de confusão em que vivem os dublinenses segundo o autor, e também pelo perambular sem rumo pelas ruas da cidade, o que em "Arábia", "Um encontro", "Uma pequena nuvem" e "Dois galanteadores" constitui praticamente toda a ação das histórias. Novamente é possível inferir, dessas temáticas constitutivas dos contos, fatos que são diretamente relacionados à vida do autor tornando-se matéria prima para a construção ficcional.

No conto "Arábia", narrado em primeira pessoa, o protagonista perambula, primeiramente dentro de casa, nos andares inferior e superior, à espera da chegada do tio, com a moeda que o permitirá visitar o bazar. Logo após, pelas ruas que levam à estação de trens e pelo bazar, que se torna pouco iluminado e vazio, levando a personagem a vivenciar sua epifania quando as luzes são totalmente apagadas. Há registros, segundo Ellmann, de que um bazar itinerante, de mesmo nome, visitou Dublin quando Joyce era criança. É possível perceber, portanto, em Joyce, a memória funcionando como um recurso estilístico e formal para a construção literária, o que vem a 
corroborar a ideia de muitos teóricos de que a escrita pode ser uma espécie de extensão do ato de rememorar.

Os estudos literários são povoados por diversas definições de memória enquanto elemento constitutivo da narrativa literária. Segundo Erll (2004), algumas das categorias apresentadas são: memória da literatura (que se manifesta nos textos através de referências textuais); memória na literatura (mímesi, encenação da memória, mostra o funcionamento desta na ficção através de procedimentos estéticos) e, finalmente, a literatura como veículo da memória coletiva. Por exemplo, no conto "Arábia", a lembrança da visita à feira pode ter sido o fator desencadeador da ficção. O texto é composto por lembranças, cenas evocadas pela memória e que, através do processo criativo, tornam-se outras histórias, vivenciadas, agora, ficcionalmente, pelas personagens criadas pelo autor.

Em "Uma pequena nuvem" e "Dois galanteadores", a narrativa circular dos protagonistas que perambulam pelo centro de Dublin, numa quase transposição do mapa topográfico real para a Dublin fictícia, permite ao leitor ter ideia da medida da estagnação nos dublinenses de Joyce: as personagens perambulam sem rumo certo e, no final das histórias, não existe mudança significativa da forma como iniciaram os contos. O que prevalece é o sentimento de vazio existencial e a falta de perspectiva quanto ao dia seguinte.

Assim estão constituídos os contos: cidadãos de Dublin perdidos metafórica e literalmente pela cidade, em busca de um sentido, de uma resposta, que se apresentam, ao final da história (sem avanço significativo algum na ação), inexistentes. As histórias de Joyce estão repletas do "sem sentido" humano, do vazio das buscas sem destino certo, como se as caminhadas incertas dos cidadãos de Dublin formassem uma espécie de metonímia de uma concepção da vida, em que o tempo de caminhada consiste na verdadeira história.

A grande crítica contida nos contos de Joyce foi quanto à paralisação do povo irlandês. Muito mais que uma característica inata dos conterrâneos do escritor, essa paralisação pode ser considerada fruto da prolongada exploração britânica e da interferência do catolicismo na sociedade e na vida privada dos cidadãos. A coesão das histórias dos contos acontece por uma ordem que 
representa os estágios da vida de um homem, da infância à vida adulta. Cada conto representa, individualmente, parte desses estágios.

Ao colocar a Dublin real como referência, tornando-a, inclusive, uma das personagens do livro, trazendo nomes de ruas e citações de lugares específicos, Joyce colabora para a formação da identidade irlandesa. Ele fala da cidade, mas fala principalmente do homem que a habita. E, ao retratar o ser humano, dá à obra dimensão universal. O mote dos contos está nos conflitos individuais. Para Francesca Valente (2003), Dublinenses é a revelação de toda uma cidade. Cada história apresenta uma verdade desagradável e todas essas verdades em conjunto revelam um estado geral de paralisia que, na visão de Joyce, foi a essência de Dublin em seu tempo.

Tendo imposto a si próprio o afastamento do cenário de sua obra, Joyce construiu a Dublin ficcional a partir de lembranças suas e de colaboradores, através de cartas. Sendo assim, o deslocamento influenciou em seu trabalho, e a memória foi utilizada enquanto ferramenta para a construção da narrativa. Michel de Certeau (2013), em sua obra $A$ invenção do cotidiano: 1. Artes de fazer, explica que a mobilização da memória é indissociável de uma alteração, que advém de uma circunstância estranha, constituindo-se na arte da relação entre um pormenor concreto e uma conjuntura sugerida, e é operada pela produção de uma conveniência. A memória "se mobiliza voluntariamente ao que acontece - uma surpresa, que ela está habilitada a transformar em ocasião" (CERTEAU, 2013, p. 150).

Segundo os estudiosos de Joyce, ele perguntava muito sobre Dublin nas cartas que trocava com amigos e parentes. A partir disso, é possível inferir que Joyce captou, esteticamente, o que precisava para, somando-se a suas lembranças, construir sua Dublin ficcional. Buscava que a banalidade realística do cotidiano instigasse sua imaginação. Afastado, corria o risco de que a cidade se tornasse "uma névoa em seu cérebro", de perder sua referencialidade espacial e, com isso, perder os elos e a base identitária com seu espaço ficcional. Então ele manteve esse vínculo vivo através das correspondências.

Além de ferramenta na composição, a memória pode ser identificada enquanto elemento constitutivo da narrativa, como em Eveline, em que a epifania da protagonista se dá quando escuta um realejo e lembra da última |120| 
noite da mãe e da promessa que havia feito de cuidar da casa. "Ao longe na avenida ouvia-se o som de um realejo. Ela reconheceu a melodia. Estranho que surgisse justo naquela noite para lembrá-la da promessa feita à mãe" (JOYCE, 2012, p. 35). Aqui, assim como a memória pode ter funcionado como elemento desencadeador da criação ficcional no autor, é possível ver a rememoração desencadeando narrativas memorialísticas nas próprias personagens. São os mecanismos da memória tornados, eles próprios, matéria narrada.

Os contos referentes à infância são rememorações do narrador em primeira pessoa que parecem ter sido empreendidas a partir de um longo espaço de tempo, pois o narrador lança um olhar de maturidade sobre as emoções juvenis. "Dia de hera na sala do comitê" também está estruturado a partir das reminiscências das personagens, que refletem sobre os benefícios que o político Charles Parnell poderia ter conseguido para a Irlanda e do quanto a situação política mudou desde sua morte.

Quanto à forma como as personagens dos contos veem a si mesmas, sua autoidentidade, há uma estreita relação com o sentimento de identidade do povo irlandês, provavelmente apreendido por Joyce na infância, bem como nas cartas que trocava. Assim como os irlandeses, as personagens se sentem inferiorizadas devido à prolongada exploração britânica. John Orr explica que o povo irlandês elaborou o estereótipo do cidadão típico dentro da memória coletiva de um povo dominado, lembrando, por exemplo, "the potato famine, the brutality of the British navy and the arrogance of the empire, nostalgia for the prosperous trading Ireland which 'existed' before the English invasion" (ORR, 1989, p. 63).

James Joyce acreditava que a raiva irlandesa se alimentava nas sementes do ódio que haviam, há muito, sido semeadas pelos mesmos motivos da inércia na sociedade. Essa memória coletiva é construída por um senso de injustiça que é reduzido à raiva com o passar das gerações, bem como a História dessa nação injustiçada é declamada a ponto de se converter em idealizada. O escritor transfere essa visão para a forma como as

\footnotetext{
5 "A fome gerada pela crise das batatas, a brutalidade da marinha britânica e a arrogância do império, nostalgia de um período de prosperidade no comércio irlandês que existiu antes da invasão inglesa".
}

Revista Eletrônica Literatura e Autoritarismo: Narrativa Testemunhal e Relações Históricas - ISSN 1679-849X |121| http://cascavel.ufsm.br/revistas/ojs-2.2.2/index.php/LA/index 
personagens veem a si, a exemplo de Maria, do conto "Terra", que vive imersa em um passado mais confortável para ela que o presente e não sonha porque não conhece possibilidades de mudança em sua realidade.

Alguns fatos trazidos à luz na narrativa joyceana, que têm raiz em um acontecimento rememorado, passaram por duas etapas de recordação: uma quando a pessoa solicitada, tia Josephine, por exemplo, lembra e escolhe as palavras com que contar ao escritor nas cartas, e outra quando a essa lembrança somam-se as memórias despertadas no próprio James que, por sua vez, "recorta" o que lhe é interessante para compor uma história ficcional, e também escolhe as palavras com as quais irá alterar esse acontecimento real duplamente rememorado e editado. Os eventos lembrados são acionados conforme as experiências posteriores, que os alteram, e também conforme as necessidades do presente.

Sobre o esquecimento a que Joyce estava sujeito sobre o seu espaço uma vez que havia se distanciado da Irlanda, Paul Ricoeur (2007) atribui importância central no processo de organização da memória. Para o autor, mesmo sendo a memória uma luta contra o esquecimento, este não é seu inimigo. Ele considera que o esquecimento pode estar tão confundido com a memória, que pode ser considerado como uma de suas condições. A relação paradoxal do esquecimento com a memória implica em diferentes maneiras de ativação desta. Ricoeur (2007) distingue, inicialmente, a partir de Aristóteles, entre "evocação simples" e "busca" ou "esforço de recordação". No primeiro caso, a lembrança ocorre espontaneamente, enquanto que no segundo ela é procurada, havendo um trabalho investigativo. Sendo assim, a recordação pressupõe, para que possa ocorrer, o esquecimento.

Quando solicitados por Joyce a lembrar determinados episódios dos moradores ou da história de Dublin, cada amigo/familiar lembrava de acordo com suas próprias emoções e vivências e, é possível que, às vezes, acrescentassem à lembrança do real "floreios" e já entregassem o fato contado com adicionais de criatividade. Esses amigos e parentes solicitados traduziram em palavras os registros de suas memórias e consciências.

São as vozes da memória que chegam da distância e se transformam em proximidade. São as vozes da memória que 
adquirem, pela costura dos fragmentos das lembranças, dimensão de tecido social e de identidades coletivas (DELGADO, 2010, p. 46).

Muito mais que lembrar histórias, as cartas tinham para Joyce a função de povoar o imaginário presente do escritor com as cores de Dublin. Elas eram o sotaque, os trejeitos, os cheiros, o clima da cidade que ele queria que estivesse em sua obra. Cada relato recebido em carta continha em si um amálgama maior: a inserção do leitor na comunidade dublinense.

\section{Considerações finais}

Em Dublinenses, Joyce disseca a sociedade da capital irlandesa do início do século $\mathrm{XX}$, oferecendo ao leitor a possibilidade de construir uma rede de sentidos e nexos que reiteram o vínculo entre Literatura, Cultura e História. Não há felicidade ou realização nos contos, que ao invés disso retratam solidão, frustração e melancolia. O "Minotauro da paralisia" avança da esfera individual até as esferas pública, religiosa e artística de Dublin. Apesar de o escritor debruçar-se sobre questões particulares a uma região, ele fala de dramas universais. A tônica de cada narrativa é a representação de sua gente, de um determinado espaço, dos hábitos, das relações interpessoais, dos códigos culturais que interditam e limitam suas ações. Ao conceder voz aos dublinenses, as descrições dão espaço para as dores e mágoas de personagens que se tornam humanos e verossímeis aos olhos do leitor.

Evidenciando os muitos paradoxos dos quais são constituídos os fazeres literários, James Joyce, o escritor autoexilado que escreve sobre sua cidade natal a partir de lembranças remotas e cartas, transpõe para seus contos as rememorações de sua infância acerca de Dublin e as impressões adquiridas através das leituras das cartas. As possíveis e prováveis lacunas existentes em sua memória, e interpretações dos relatos que recebe, são preenchidas com a capacidade única do escritor irlandês de criar, de construir mundos interiores e exteriores agudos de sensibilidade e contradições humanas.

Revista Eletrônica Literatura e Autoritarismo: Narrativa Testemunhal e Relações Históricas - ISSN 1679-849X |123| http://cascavel.ufsm.br/revistas/ojs-2.2.2/index.php/LA/index 


\section{Referências}

CANDIDO, Antonio. Literatura e sociedade. 8. ed. São Paulo: T. A. Queiroz, 2000.

CERTEAU, Michel de. A invenção do cotidiano: 1. Artes de fazer. 20. ed. Trad. Ephraim Ferreira Alves. Petropólis, RJ: Vozes, 2013.

CORRÊA, Alan Noronha. How to Build an Irish Artist: Joyce's First Portraits of Dublin. Porto Alegre: UFRGS, Instituto de Letras, 2012 (Dissertação de Mestrado).

DAICHES, David. James Joyce: The artist as Exile. In: College English, Vol. 2, no 3 (dez. 1940), págs. 197-206. Acesso em JSTOR em 28 de janeiro de 2015.

DELGADO, Lucilia de Almeida Neves. História oral: memória, tempo, identidades. Belo Horizonte: Autêntica, 2010.

ELLMANN, Richard. James Joyce. Trad. Lya Luft. São Paulo: Globo, 1989.

ERLL, Astrid; ROGGENDORF, Simone. Kulturgeschichliche Narratologie: die Historisierung und Kontextualisierung kultureller Narrative. In: NÜNNING, Ansgar; NÜNNING, Vera (Org.). Neue Ansätze in der Erzähltheorie. Trier: WVT, 2002.

JOYCE, James. Dublinenses. Trad. Guilherme da Silva Braga. Porto Alegre: L\&PM, 2012.

O’BRIEN, Edna. James Joyce. Rio de Janeiro: Objetiva, 2001.

ORR, John. The Making of the Twentieth-Century Novel - Lawrence, Joyce, Faulkner and Beyond. Hong Kong: The Macmillan Press, 1989.

RICOEUR, Paul. A memória, a história, o esquecimento. Trad: Alain François et al. Campinas, SP: Editora da Unicamp, 2002.

VALENTE, Francesca. Joyce's Dubliners as Epiphanies, 2003. Disponível em: <http://www.themodernword.com/joyce/paper_valente.html>. Acesso em: 26 jan. 2015.

VIZIOLI, Paulo. James Joyce e sua obra literária. São Paulo: EPU, 1991. 